\title{
New functionalities in Orphanet for orphan drugs, $R \& D$ and marketing authorisations to better serve the rare diseases community
}

\author{
Virginie Hivert, Natalia Martin, Marc Hanauer, Ségolène Aymé*
}

From 5th European Conference on Rare Diseases (ECRD 2010)

Krakow, Poland. 13-15 May 2010

The data contained in the Orphanet "Orphan Drugs" database is extracted from official sources. This data includes a list of all substances which have been granted an orphan designation for a disease(s) considered as rare in Europe, whether further developed to become drugs with marketing authorisation (MA) or not. The Orphanet database also includes drugs without an orphan designation as long as they have been granted a MA with a specific indication for a rare disease. Orphanet also publishes a quarterly report ("Orphanet Report Series") listing orphan drugs on the European market with or without prior orphan designation. In order to improve access to Orphanet's rich database of information and resources, the search engine has been recalibrated to render data more accessible. In addition to existing search options (by drug or disease), four new sub-tabs improve the visibility of information pertaining to orphan drugs, allowing users to search by a wider range of criteria. Several alphabetical lists of designated products, orphan-designated products with MA, substances and drug trade names are now available. New advanced search options allow users to refine their search by sponsor, MA holder and ATC (Anatomic, Therapeutic, Chemical) category. Substances are now clearly separated from trade names in the results pages: trade names are used solely for products granted MA, whereas substances with orphan designation status (prior to MA) are referred to by their active molecule. Additionally, each substance or trade name is linked to the "Clinical trials" sub-tab of the "Research and trials" tab. Users can retrieve clinical trial(s) that are (or have been) performed for a particular drug. These can also be searched

${ }^{*}$ Correspondence: segolene.ayme@inserm.fr

Orphanet - INSERM SC11, Plateforme Maladies Rares, 96, rue Didot, Paris 75014, France by a wider range of criteria (disease concerned, principal investigator by country, sponsor or clinical trial category). These features are available in all five languages of the Orphanet website.

Published: 19 October 2010

doi:10.1186/1750-1172-5-S1-P25

Cite this article as: Hivert et al: New functionalities in Orphanet for orphan drugs, R\&D and marketing authorisations to better serve the rare diseases community. Orphanet Journal of Rare Diseases 2010 5(Suppl 1):P25.
Submit your next manuscript to BioMed Central and take full advantage of:

- Convenient online submission

- Thorough peer review

- No space constraints or color figure charges

- Immediate publication on acceptance

- Inclusion in PubMed, CAS, Scopus and Google Scholar

- Research which is freely available for redistribution

Submit your manuscript at www.biomedcentral.com/submit
BioMed Central 